Cad.Est.Ling., Campinas, (44):11-17, Jan./Jun. 2003

\title{
INGEDORE KOCH E OS SEGREDOS DO TEXTO
}

\author{
LUIZ ANTÔNIO MARCUSCHI \\ (UFPE/CNPq)
}

\begin{abstract}
"Nasci em Eisenbach, pequena cidade medieval situada no coração da Alemanha, celebrizada por ter sido o berço de Johan Sebastian Bach e por abrigar o castelo da Wartburg, onde Martin Luther traduziu a bíblia. Menos auspicioso foi o ano de meu nascimento 1933 -, tragicamente marcado pela ascensão de Adolph Hitler ao poder.

Contando cinco anos de idade, no início de 1939, pouco antes de estourar a guerra, meus pais viram-se obrigados a imigrar para o Brasil, vindo a fixar residência na cidade de São Paulo. Foi no Brasil, portanto, que cresci e que se processou toda minha formação, de modo que, ao atingir a idade legal, assumi conscientemente a nacionalidade brasileira."
\end{abstract}

Estes são os dois primeiros parágrafos do humano, rico e denso Memorial de Ingedore Grünfeld Villaça Koch preparado para o Concurso de Professor Titular de Lingüística no Instituto de Estudos da Linguagem (IEL), da Universidade Estadual de Campinas (UNICAMP), em dezembro de 1999. Na realidade, meu contato com essa história começa vinte antes, quando aprendi a conhecê-la no início dos anos oitenta, no Departamento de Português da Pontifícia Universidade Católica de São Paulo (PUC/SP). Foi uma agradável descoberta para mim encontrar ali uma interlocutora com os mesmos interesses e que se tornaria uma grande amiga. Surpreendente naquele momento foi conhecer alguém que dominava com perfeição o idioma alemão, o que lhe dava a imensa vantagem de trazer para o nosso meio lingüístico idéias de autores desconhecidos por brasileiros. Lia e citava já naquele tempo os trabalhos de Roland Harweg, Elizabeth Gülich, Harald Weinrich, Paul Hartmann e muitos outros ignorados por aqui. Desde então não paramos de interagir, seja em intensa correspondência pessoal, projetos de pesquisa conjuntos, mesas-redondas em congressos, bancas examinadoras, cursos em parceria e trabalhos produzidos em co-autoria. Isto me deu o privilégio de conhecer mais de perto esta notável figura humana em todos os sentidos. E é sobre este belo ser humano que vou falar aqui.

Naquele início dos anos oitenta, eu pouco conhecia da situação dos estudos lingüísticos no Brasil e não sabia onde a professora e pesquisadora Ingedore Koch 
poderia ser situada nesse contexto. Contudo, não foi difícil localizá-la, sobretudo quando vi sua tese de doutorado sobre a argumentação inserida na linha da lingüística da enunciação, saindo do enquadre tipicamente formal. Mais preciso ainda se tornou esse enquadre teórico original quando tomei contato com seus trabalhos em Linguística de Texto que viriam a ser uma referência obrigatória. Aquele trabalho naquele contexto não foi fácil, pois ali estava um momento particularmente difícil para esse tipo de investigação. O gerativismo andava na crista da onda e as linhas de trabalho ditas "discursivas" não eram bem-vistas. Foi a qualidade do trabalho aliada à intensidade das investigações relacionadas ao ensino de língua que resultou uma perspectiva teórica hoje madura e influente na renovação dos critérios, categorias e propostas de pesquisa e ensino da língua. O papel de incentivadora que Ingedore Koch teve e ainda tem nesse complexo processo de reordenamento teórico em âmbito nacional é não apenas indiscutível, mas visível na sua presença como mentora e teórica de primeira água.

Autora de mais de vinte livros e uma centena de artigos em revistas, coletâneas e anais, sempre reproduzidos em fotocópias onde chegam, sua forte influência se faz sentir na aplicação direta de seus ensinamentos no ensino e entre os pares na academia, onde figura como fonte de inspiração teórica em projetos de pesquisa, teses e dissertações. Não exagero ao afirmar que Ingedore Koch contribuiu de modo decisivo para a consolidação da Lingüística Textual entre nós e também para a afirmação dessa linha de trabalho como uma das mais produtivas e inovadoras. Isso não é pouco nem ocorre com freqüência no meio acadêmico. Para mim tem sido um prazer especial acompanhar este movimento por vezes frenético ao longo deste último quarto de século solidamente incentivado por essa pesquisadora incansável e sempre disposta ao diálogo.

Quanto a esse aspecto de pesquisadora incansável, gostaria de retornar a alguns dados do Memorial sem a intenção de construir aqui uma biografia sumária, mas com o intuito de frisar aspectos que marcam a trajetória de Ingedore Koch como uma estudiosa exemplar e pertinaz que, segundo ela própria costuma lembrar, tomou como modelo a figura do João Teimoso, que não pára e não cai. Professora desde os 15 anos, quando ainda cursava o colegial, não teve vida folgada. Formada no curso secundário com uma bolsa obtida pelo mérito de ser a primeira colocada, isso viria a se repetir depois nos Cursos de Graduação e Pós-Graduação. Desde seu primeiro concurso para prof Assistente-Mestre em 1976, na PUC/SP, até seu último concurso para Prof Titular em dezembro de 1999, na UNICAMP, foram nove concursos realizados com nota máxima. Nesse meio tempo, fez duas carreiras acadêmicas consecutivas e completas, uma em Universidade Particular e outra em Universidade Pública, conhecendo muito bem os dois ambientes de trabalho. É durante esse trajeto acadêmico que desenvolve seu projeto como investigadora fiel a uma temática que trabalha com aprofundamento cada vez maior.

Observando com cuidado este percurso e as condições que o antecederam, descobri aqui um caminho cuidadosamente trilhado. Seu primeiro Curso Superior foi na área de Direito, que por decisão pessoal nunca chegou a exercer, porque sempre se achou vocacionada para o magistério. Concluído o Curso de Direito em 1956, casada e com dois filhos pequenos, interrompe seus estudos universitários por 16 anos, até 1972, quando decide fazer o Curso de Letras, realizando um velho sonho de sua adolescência. 
Assim, em 1975, obtém a licenciatura plena em Letras: Português - Língua e Literatura e no mesmo ano inicia seu Curso de Mestrado em Língua Portuguesa na PUC/SP, concluindo-o em 1977. Era o começo de uma agora ininterrupta e brilhante carreira acadêmica.

Foi ainda durante o Curso de Mestrado, em 1976, que iniciou a carreira universitária como professora Auxiliar na PUC/SP com uma cadeira de Morfossintaxe do Português na graduação. Sobre o tema, viria a publicar vários trabalhos em coautoria com Maria Cecília Perez de Souza e Silva. Para mim, este aspecto marca uma das qualidades que admiro na investigadora Ingedore Koch, ou seja, a perspicácia para o detalhe e para o exemplo certo que frutifica na teoria e na análise. Recentemente, em conferência pronunciada no Recife, eu observava a minúcia com que ela analisava os exemplos apresentados a um auditório atento para confirmar as posições teóricas expostas. Ao meu ver, aquele início no interior da teoria gramatical lhe daria sólida formação para depois tratar aspectos textuais que nem sempre são analisados no grau de precisão que a caracteriza.

A dissertação de Mestrado defendida em 1977 versava sobre "Os Sintagmas Preposicionados com Modificadores Nominais”, mas este percurso sofreria logo em seguida uma guinada para os processos de textualização, que viriam a ser seu horizonte de trabalho até hoje, com um amadurecimento constante e a incorporação de novas propostas analíticas e visões teóricas. Aqui está uma trajetória clara e uma decisão muito coerente para fixação num campo de trabalho que desde os anos oitenta vem sendo por ela desenvolvido e aprofundado. O fascínio pelo texto e seus segredos é notável em todas as suas exposições orais e escritas, feitas com a paixão de quem sente prazer no trabalho e tem consciência de sua contribuição.

Tornou-se doutora em Língua Portuguesa em 1981, com a tese "Aspectos da Argumentação em Língua Portuguesa", que ficou conhecida pelo estudo pioneiro lançado pela Editora Cortez em 1984. Como já disse, este trabalho, ainda hoje atual e muito utilizado, inicia efetivamente a carreira da autora na área de produção e compreensão textual. Tive o imenso prazer de fazer a apresentação a essa obra e confesso que ainda me sinto orgulhoso com o convite para apresentar uma investigação com cujas idéias me identifico muito, já que a noção de argumentação ali exposta não é aquela da tradição aristotélica nem aquela dos lógicos formais, mas uma situada no contexto da semântica argumentativa, com sensibilidade para os processos dialógicos. Nesse trabalho podem ser identificados vários aspectos que mais tarde seriam retomados no contexto do processamento textual. Um deles foi o estudo detalhado dos conectivos que mereceu tanta reflexão e produziu grandes frutos na análise textual. Assim, ao meu ver, com a investigação para o doutorado encaminhava-se a reflexão para a semântica e a pragmática na interface com o discurso, o que definiria de maneira decisiva a carreira de pesquisadora na linha da Lingüística Textual, da qual continua uma grande incentivadora, tendo lançado há vinte anos, em co-autoria com Leonor Lopes Fávero, o pioneiro "Lingüística Textual - Uma Introdução". E depois lançaria muitos outros trabalhos levando adiante suas posições com um trabalho de indiscutíveis marcas pessoais que tanto influenciaria a última geração de lingüistas no Brasil. 
O que impressiona nesta trajetória é a determinação obstinada no adotado estilo de um João Teimoso. Quem diria que após dezesseis anos de interrupção dos estudos, se tornaria possível reiniciar a vida acadêmica, vindo a concluir em menos de dez anos, entre 1972 e 1981, uma Graduação, um Mestrado e um Doutorado com publicações que vinte anos depois continuam atuais? Após o doutorado, durante os próximos cinco anos, até ingressar na UNICAMP, Ingedore Koch se notabiliza nacionalmente por suas investigações e publicações na área de Lingüística Textual sobretudo em torno dos dois temas mais debatidos na época: coesão e coerência. Basta dizer que a qualidade de seu trabalho nessa época a qualificou para ser convocada a trabalhar na UNICAMP, onde teria o papel de introduzir e fomentar a linha de pesquisa em Lingüística Textual no contexto da Análise do Discurso. É o que fará com grande repercussão e dedicação nos seus cursos e orientações na Pós-Graduação. Hoje, com quase meia centena de teses e dissertações orientadas nessa área, ela marca presença na maioria dos estados brasileiros.

Todos sabemos que um dos aspectos mais pesados de nossa vida acadêmica é a intensidade das exigências de reuniões, atividades burocráticas, montagem de projetos, participação em comissões e por aí afora. Isso toma tempo, desvia da pesquisa e às vezes impede a renovação teórica. Como eu tenho acompanhado de perto a dedicação de Ingedore Koch a este tipo de participação e de modo especial os cursos, as orientações, bancas de teses, concursos, conferências, mesas em congressos, atuação em comissões e outras atividades dessa ordem, confesso minha admiração pelo seu senso para distribuição do tempo e sua imensa energia e capacidade de trabalho. E mais: isso tudo não impediu a continuidade das leituras e a renovação em cursos de PósDoutorado na Alemanha, Holanda e França com pesquisadores de grande expressão em sua área de trabalho. Essas constantes viagens e esses variados contatos lhe deram uma visão ampla de todos os problemas da Lingüística Textual, o que se pode observar em alguns de seus estudos recentes de acurada revisão das investigações no processamento textual.

Sempre admirei pessoas que conseguem ter uma visão de conjunto de suas áreas de trabalho. E este é um dos lados fascinantes de Ingedore Koch que exibe uma extraordinária capacidade para visões de conjunto de áreas teóricas e temas globais nucleares com aguda percepção do que está sendo discutido. Essa visão global aliada à sensibilidade para novas questões não a desvia de seu foco de trabalho que continua ligado ao processamento textual e à textualidade. A rigor, esta "Dama do Texto" nunca se afastou do núcleo de suas preocupações teóricas desde os anos oitenta. Contudo, eu seria injusto se reduzisse seu trabalho ao campo da textualidade, pois ela também incursiona pela semântica, a sintaxe e a morfologia, áreas em que tem trabalhado na graduação e que muitas vezes transparecem em suas análises dos textos orais e escritos. Aliada a essa visão de conjunto de todo o fenômeno lingüístico está a capacidade de exposição serena, num estilo muito cuidado e sempre adequado ao público para o qual escreve ou fala. Isto a torna lida por todos, sejam os teóricos mais exigentes ou os professores de Primeiro e Segundo Graus em sala de aula. Poucos têm essa maleabilidade, perspicácia, sabedoria e leveza no trato da coisa teórica. 
Essa serenidade na exposição estende-se ao trato das pessoas no dia-a-dia, no ambiente de trabalho e no debate teórico. Senti e vivi este lado em todos estes aspectos. Experiência muito agradável foi seu marcante papel de coordenadora do grupo de análise textual no contexto do Projeto da Gramática de Língua Falada (organizado e dirigido por Ataliba de Castilho), do qual fiz parte. Nesse grupo, ela sempre 'cobrou' as tarefas com delicadeza e incentivou os participantes a se engajarem e produzirem como uma equipe sem perder a individualidade. A habilidade de harmonizar as pessoas e deixá-las à vontade para produzirem em suas próprias linhas de ação era uma de suas marcas. Sob este aspecto, chama atenção sua notória capacidade de trabalhar em coautoria. Parte de sua obra foi realizada nesta condição co-autoral. Primeiro com a colega de trabalho na PUC/SP, Maria Cecília Perez de Souza e Silva, na área de Morfologia e Sintaxe e, mais tarde, com a mesma Cecília, na área de língua falada no contexto do Projeto da Gramática da Língua Falada. E então com Leonor Fávero sobre Lingüística Textual, e com seu orientando de Doutorado na UNICAMP, Luiz Carlos Travaglia, com quem escreveu vários de seus best-sellers. Esta disposição para trabalho em conjunto é uma marca de pessoas generosas, capazes de dividir seu saber mesmo quando já são conhecidas e têm uma vida acadêmica estabilizada. Eu mesmo tive o prazer de produzir com a Inge dois textos sobre problemas de referenciação e me alegra lembrar que foi uma experiência pessoal de total liberdade na seleção dos autores, posições e idéias na hora de produzir os trabalhos. Quando escrevemos aqueles dois textos junto, eu jamais senti algum tipo de imposição ou de coerção e tudo se deu de forma natural. Isso a tal ponto que hoje não saberia de fato dizer o que é de um ou de outro naqueles textos, tal a simbiose das idéias.

Depoimentos de seus orientandos de Mestrado e Doutorado revelam uma convivência agradável, carinhosa e amiga que exorbita a preocupação acadêmica. Basta ler os agradecimentos nas teses e dissertações por ela orientadas para ver o que seus alunos sentem. Já presenciei mais de uma vez a orientadora Ingedore preocupada e envolvida como amiga com orientandos que passavam por dificuldades pessoais. Seu comportamento amigo é típico de pessoas que não sabem desvincular a atividade de formação intelectual do companheirismo do ser humano que está sendo formado. Incapaz de esconder dos colegas e amigos suas fontes, seus trabalhos em andamento, mesmo correndo o risco de usurpação indevida - o que não é incomum na vida acadêmica -, ela sempre põe tudo à disposição de forma aberta e generosa. Gostaria que você soubesse, Inge, de minha profunda admiração por este seu lado humano e pela já lembrada capacidade de trabalho, seja na leitura atenta de projetos, teses, artigos e livros sugerindo mudanças e dando contribuições.

Muito mais haveria a dizer sobre o extraordinário ser humano que é a amiga e colega Inge, mas agora pretendo me deter de modo particular em considerações sobre a evolução intelectual da hoje reconhecida pesquisadora Ingedore Koch nestes últimos 25 anos. Exemplar e profícua é esta caminhada que vai de 1978 a 2003. Variado e rico é o percurso intelectual que a traz ao estágio atual, quando lança obra de título tão sugestivo, "Desvendando os Segredos do Texto", influenciada pelas novas posições teóricas provindas da área sócio-cognitiva. Neste, como em outros trabalhos recentes, seu tema central continua sendo o processo de produção e compreensão textual. O que 
muda é o enfoque e a base da observação. Sua preocupação atual é explicar como os referentes são fabricados na prática social, o que exigirá uma nova noção de língua e uma mudança de visão da relação entre linguagem e mundo com a despedida das teorias da referência extensionalista. Esta renovação teórica dentro de uma fidelidade temática é uma de suas marcas típicas. Eu diria que a visão teórica de Ingedore Koch veio se desenvolvendo desde os anos oitenta até hoje progressivamente numa linha cada vez mais filosófica e rumo a processos mais amplos e uma compreensão mais holística da realidade lingüística. Trata-se de um amadurecimento que se deu na perspectiva de uma maior compreensão do mundo como um grande texto que tem mistérios e segredos que a linguagem encapsula e constitui e que nós precisamos desvendar. Foi uma trajetória da sintaxe para a cognição; do co-texto para a interação.

No início dos anos oitenta, a Lingüística Textual enfatizava os princípios de coesão e coerência na textualização e a preocupação voltava-se para os critérios da construção do tecido textual, tal como Ingedore Koch os desenvolveu. Havia uma dedicação maior ao estudo dos aspectos conectivos e procedimentos morfossintáticos da textualidade com uma acentuada atenção para o texto escrito. À época predominava a noção de texto como "unidade comunicativa" na perspectiva da pragmática austiniana e goffmaniana com ênfase nos atos de fala, mas as preocupações com o contexto e a interação social nunca ficaram de lado. Reveladores deste aspecto são os textos da autora sobre a interação verbal em contextos sociais, escritos na década de oitenta. Este é um aspecto novo que entra em suas considerações com a assimilação da Análise da Conversação em suas pesquisas. São também desse período os trabalhos sobre a argumentação, tipologia textual, modalidades e polifonia. Estes são os temas centrais para cuja discussão a pesquisadora muito contribuiu no contexto da lingüística brasileira. Característicos para este período são a já lembrada tese sobre a "Argumentação e Linguagem" e os livros sobre coesão e coerência textual e boa parte dos trabalhos sobre oralidade que apenas iniciavam.

Os anos noventa representam uma guinada decisiva rumo a um compromisso maior com a perspectiva sócio-interativa mudando em vários aspectos a noção de língua, texto e atividades de compreensão. Parte significativa dos trabalhos deste período situam-se no contexto da investigação textual-interativa e eles são desenvolvidos no âmbito do já lembrado projeto da Gramática da Língua Falada, contemplando em especial o texto oral. Assim, nos anos noventa, o texto oral entra de forma mais intensa nas preocupações da pesquisadora. Para esta fase são característicos os trabalhos da obra "Inter-ação pela Linguagem”, embora ali estejam investigações do final da década anterior. São de se registrar ainda as extensas análises sobre o fluxo informacional, na fala e na escrita, tendo como núcleo a organização tópica do texto na perspectiva funcional de Praga que é por ela revisitada e revitalizada de maneira inovadora. Dedica-se de modo particular ao problema da dimensão ilocutória do texto e à produção de sentido; inicia as reflexões sobre a atividade inferencial e os processos de referenciação, tendo eu o prazer de elaborar juntamente um trabalho sobre o tema. Surgem, nesta esteira, os trabalhos sobre aspectos funcionais na construção de sentido com um discreto distanciamento das posições iniciais e um caminho rumo a premissas decididamente sócio-cognitivas. Típico para este período é o conjunto de textos da obra 
O Texto e a Construção dos Sentidos, que marca um aprofundamento de temas anteriores e ao mesmo tempo um acréscimo com a visão sócio-interacional da linguagem e a análise das atividades cognitivo-discursivas.

A perspectiva teórica atual da pesquisadora Ingedore Koch, iniciada na metade da década passada, move-se na busca de um melhor entendimento da produção de sentido com base nas ações sócio-interativas não mais centradas nos procedimentos intratextuais. A imanência do artefato textual sai de foco para dar lugar à cognição. A produção textual e a construção de sentido continuam seu centro, mas com um arsenal teórico-metodológico bastante inovador e instigante. A preocupação com os processos referenciais e inferenciais, a progressão referencial e as atividades sócio-interativas na produção de sentido, situando o texto em suas condições de produção, passam para o primeiro plano. A língua perde sua aura de um sistema representacional para se transformar numa atividade de produção de sentido sócio-historicamente situada. A referenciação é vista como atividade discursivamente construída como mostram os trabalhos mais recentes de seu último livro, já lembrado aqui, com o sugestivo título "Desvendando os Segredos do texto". Segredos estes ancorados nos meandros mais complexos da cognição, tema de futuro e do futuro, grande desafio da etapa que se abre. Uma etapa que a maturidade deverá consolidar.

Para concluir precisamente por onde comecei este meu depoimento misturado com observações biográficas e avaliações muito pessoais, certamente um texto híbrido no gênero, gostaria de registrar aqui o último parágrafo do Memorial para o Concurso de Titular, agindo de forma simétrica nesta construção textual:

\footnotetext{
“Minha produção científica da última década está toda ela centrada na reflexão sobre questões relativas ao processamento (produção/compreensão) e à organização de textos quer falados, quer escritos - e, portanto, na questão da construção interacional dos sentidos. $O$ que a diferencia das fases anteriores é uma forte tônica na pesquisa dos processos e estratégias de ordem sócio-cognitiva aí envolvidos."
}

Minha querida Inge, dificilmente conseguiria eu em um parágrafo apenas resumir com tanta precisão os rumos que o seu trabalho vem tomando nestes últimos anos. Já disse aqui e repito que uma de minhas alegrias foi ser co-autor de dois trabalhos nesses temas. Resta-me, no entanto, a frustração de não ter concluído os dois livros que se acham pelo caminho e que juntos planejamos para produzir um dia e mais uma coautoria. O primeiro, sobre atividades de compreensão e, o segundo, sobre temas na área de cognição e linguagem. Muito me alegraria a retomada desses dois projetos inconclusos. 